\title{
Response of recurrent sustained ventricular tachycardia to verapamil
}

\author{
BERNARD BELHASSEN, HESCHI H ROTMENSCH, SHLOMO LANIADO \\ From the Department of Cardiology, Municipal Governmental Medical Center, Ichilov Hospital, Tel-Aviv, Israel
}

SUMMARY A 28-year-old man is described with no demonstrable organic heart disease and recurrent paroxysmal attacks of sustained ventricular tachycardia. Lignocaine and ajmaline failed to terminate the first attack but a bolus injection of verapamil succeeded. This drug was subsequently successful on six more occasions. During electrophysiological study of the eighth attack, slow intravenous administration of verapamil significantly reduced the rate of the tachycardia and prevented its subsequent reinitiation by pacing.

Two mechanisms are postulated to explain both the arrhythmia and the beneficial effects of verapamil in this case.

Verapamil is a very effective, widely used antiarrhythmic agent in the treatment of supraventricular tachyarrhythmias. ${ }^{12}$ Little is known, however, about its efficacy in treating sustained ventricular tachycardia.

We report the successful use of verapamil in terminating or slowing sustained ventricular tachycardia, and in preventing its reinitiation by pacing. On the basis of the electrophysiological properties of verapamil, the possible pathogenesis of the arrhythmia is discussed.

\section{Case report}

A 28-year-old man was admitted to hospital in March 1979 because of a recurrent attack of sustained ventricular tachycardia. He had experienced the first attack at the age of 18 and six additional attacks had occurred between October 1977 and the time of admission, for which he had been treated in another hospital. During the attacks the heart rate was 150 beats/min and the electrocardiogram showed a right bundle-branch block pattern with left axis deviation, atrioventricular dissociation, sinus capture, and fusion beats. After the attacks, the electrocardiogram showed only transient repolarisation abnormalities in the posterolateral leads, probably post-tachycardia changes.

During the first attack in October 1977, lignocaine (100 $\mathrm{mg}$ intravenously) had had no effect while the administration of ajmaline ( $50 \mathrm{mg}$ intravenously) had resulted in transient slowing of the arrhythmia from 150 to 125 beats $/ \mathrm{min}$. An intravenous bolus of verapamil ( $7.5 \mathrm{mg}$ ) administered one hour after ajmaline restored sinus rhythm after progressive slowing of the tachycardia (Fig. 1). Verapamil was the only drug administered in the six subsequent attacks and always terminated the tachycardia within three minutes of injection.

Maintenance treatment with oral quinidine sulphate ( $1200 \mathrm{mg} /$ day) failed to prevent the attacks of tachycardia; this was attributed to the patient's non-compliance. Amiodarone hydrochloride (200 mg/ day) was taken more regularly and resulted in suppression of the tachycardia for 10 months until the occurrence of the attack for which he was admitted. On admission, physical examination was normal. The electrocardiogram showed a pattern similar to that of previous attacks.

An electrophysiological study, performed during the tachycardia, showed that the cycle length was $\mathbf{4 5 0}$ ms (rate: 133 beats $/ \mathrm{min}$ ). No His potential was present before the QRS complex of the tachycardia; sinus capture beats were preceded by a His potential with an HV interval of $50 \mathrm{~ms}$. During right atrial pacing at a rate of 143 beats $/ \mathrm{min}$, fusion beats were observed and the QRS complex returned to normal with a His potential preceding each QRS complex with an HV interval of $50 \mathrm{~ms}$ (Fig. 2). When atrial pacing was ineffective or interrupted (Fig. 2), ventricular tachycardia immediately resumed. The tachycardia was terminated by a premature ventricular stimulus. During sinus rhythm, the $\mathrm{AH}$ and HV intervals were 70 and $50 \mathrm{~ms}$, respectively. Ventricular tachycardia could be induced by de- 


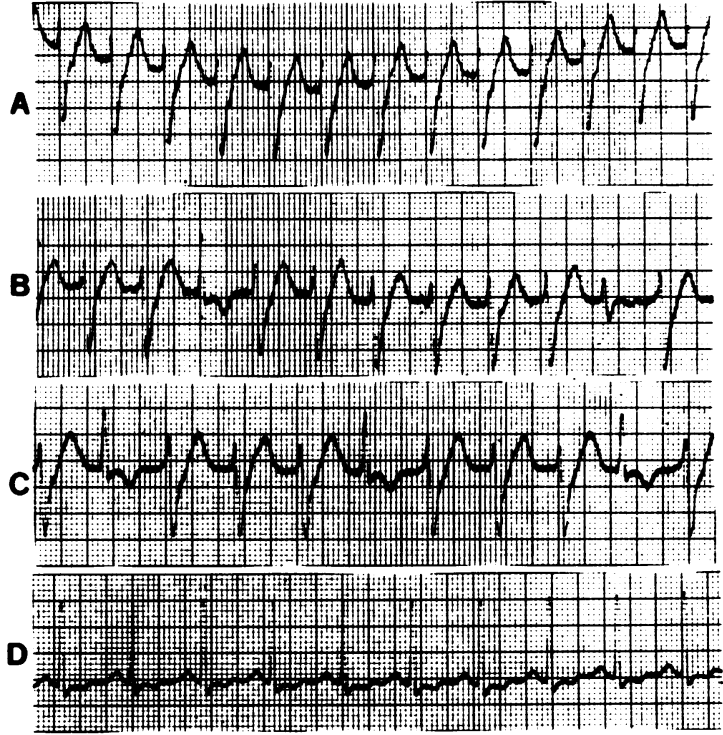

Fig. 1 Effects of a bolus injection of verapamil during ventricular tachycardia in October $1977-(A),(B),(C)$, show lead III trace and $(D)$ shows lead II. $(A)$ ventricular tachycardia at a rate of 150 beats/min. (B) One minute after a bolus of intravenous verapamil $7.5 \mathrm{mg}$. Slowing of the ventricular rate at 125 beats $/$ min is noted with sinus capture and fusion beats. (C) 30 seconds later; ventricular rate at 115 beats/min. (D) Conversion to sinus rhythm two minutes after verapamil.

livering two premature ventricular stimuli during ventricular pacing (cycle length $500 \mathrm{~ms}$ ) or by a burst of rapid ventricular pacing (180 beats/min) (Fig. 3). An intravenous bolus injection of $20 \mathrm{mg}$ adenosine triphosphate had no effect on the tachycardia.

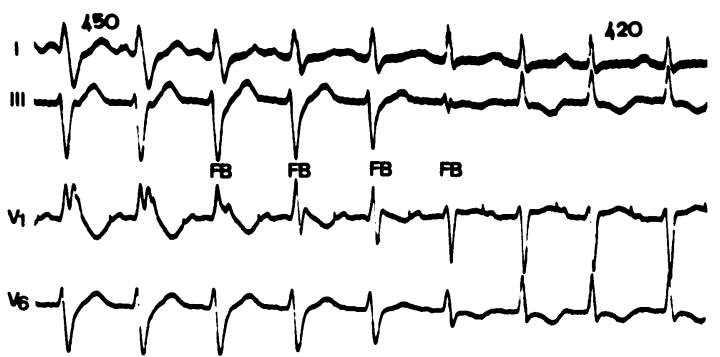

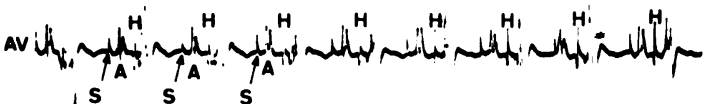

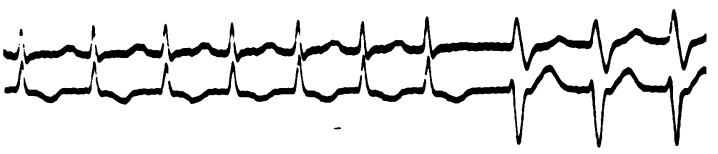

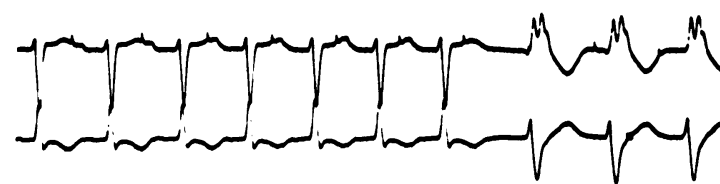

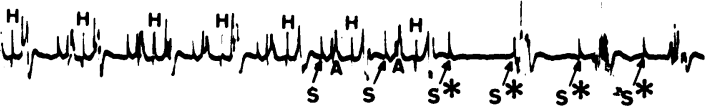

Fig. 2 Top: During ventricular tachycardia (cycle length 450 ms), right atrial pacing (cycle length $420 \mathrm{~ms}$ ) captures the ventricles and normalises the $Q R S$ complex. Note fusion beats $(F B)$. Bottom: When atrial stimulation is ineffective $\left(S^{\star}\right)$, ventricular tachycardia reappears. $A V, A V$ junction; $A$, atrial depolarisation; $H, H$ is bundle deflection; $S$, stimulus. Paper speed is $50 \mathrm{~mm} / \mathrm{s}$.

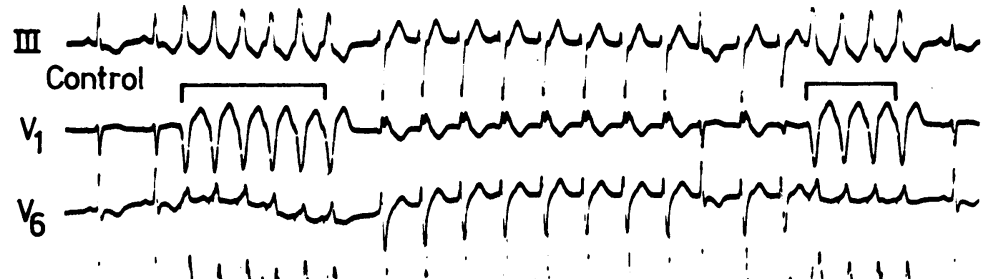

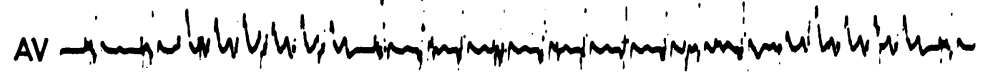

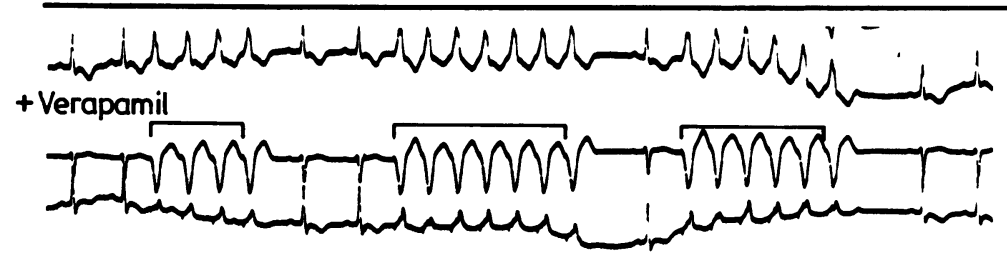

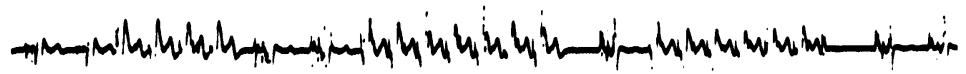

Fig. 3 Top: $A$ burst of ventricular pacing ( 180 beats/min $)$ induces and terminates the ventricular tachycardia. Bottom: After verapamil, repeated attempts to induce ventricular tachycardia by a burst of ventricular pacing are unsuccessful. Paper speed is 25 $\mathrm{mm} / \mathrm{s}$. 
Intravenous verapamil, $10 \mathrm{mg}$, administered over a three-minute period, resulted in gradual slowing down of the tachycardia from 133 to 105 beats/min. One premature ventricular stimulus was delivered to terminate the tachycardia. Subsequent repeated attempts to induce ventricular tachycardia by atrial or ventricular pacing were unsuccessful (Fig. 3).

The chest $x$-ray film, the echocardiogram, and the radionuclide ventriculogram $\left({ }^{99} \mathrm{Tc}\right)$ were all normal. Maintenance oral verapamil treatment was recommended but the patient refused to take drugs three times a day. Amiodarone ( $400 \mathrm{mg}$ once daily five days a week) was, therefore, continued and on this treatment one further attack occurred a year later which also responded to intravenous verapamil.

\section{Discussion}

The tachycardia in our patient fulfils all the generally accepted criteria of ventricular tachycardia. ${ }^{3}$ An additional useful diagnostic clue is the failure of adenosine triphosphate to alter the tachycardia. ${ }^{4}$ This has a strong transient vagomimetic effect.

The case is interesting because seven attacks of ventricular tachycardia responded to verapamil, while the arrhythmia was refractory to lignocaine and ajmaline in one instance as well as to quinidine given long term. Wellens et al. ${ }^{5}$ failed to achieve an effect with intravenous verapamil in four patients with sustained ventricular tachycardia while procainamide consistently slowed or terminated the arrhythmia. In our patient, an intravenous bolus injection of verapamil consistently terminated the tachycardia while a slow intravenous injection significantly decreased the rate of the tachycardia and prevented its reinitiation by pacing. This discrepancy is probably accounted for by different modes of administration of the drug.

The ability to initiate and terminate a tachycardia by premature stimuli delivered within well-defined time intervals suggests either a mechanism of reentry $^{6}$ or triggered automaticity. ${ }^{7}$ A re-entry mechanism may involve either slow response action potentials or depressed fast response action potentials. Since verapamil mainly inhibits the slow inward current, ${ }^{8}$ the involvement of slow response action potentials is likely. Slow response action potentials were found in infarcted human myocardium, ${ }^{9}$ but were not correlated with ventricular tachycardia. The involvement of depressed fast response action potentials is unlikely, since it has been show that only high concentrations of verapamil were able to abolish them. ${ }^{8}$ This was not the case in our patient. Triggered automaticity as a result of delayed after-potentials is another possible mechanism. Indeed, such delayed after-potentials are known to be slow channel dependent and therefore might be abolished by verapamil. ${ }^{10}$ Coumel et al. ${ }^{11}$ suggested that triggered automaticity may be involved in the pathogenesis of salvos of ventricular tachycardia in man and observed beneficial effects with verapamil.

In young patients with no demonstrable organic heart disease, a pattern of right bundle-branch block and left axis deviation, as in our case, has been assumed to represent a distinct electrocardiographic entity. ${ }^{12}$ Further attempts to treat such patients by verapamil are required in order to determine whether this electrocardiographic entity corresponds to a particular electrophysiological mechanism.

We suggest that in cases of recurrent ventricular tachycardia that are refractory to conventional treatment, verapamil, if not otherwise contraindicated, may be a reasonable alternative. Further confirmatory experience is, however, needed.

We thank Professor Nissim Kauli, Kaplan Hospital, Rehovot, for referring this patient to our department.

\section{References}

1 Schamroth L, Krikler DM, Garrett C. Immediate effects of intravenous verapamil in cardiac arrhythmias. $\mathrm{Br} \mathrm{Med}$ f 1972; i: $660-2$.

2 Krikler DM, Spurrell RAJ. Verapamil in the treatment of paroxysmal supraventricular tachycardia. Postgrad Med F 1974; 50: 447-53.

3 Touboul P, Slama R. Les critères de diagnostic des tachycardies ventriculaires. In: Actualités cardiovasculáires medico chirurgicales. Paris: Masson Ed, 1972: 146-70.

4 Motté G, Waynberger M, Lebars A, Bouvrain Y. L'adénosine triphosphorique dans les tachycardies paroxystiques. Intèrêt diagnostique et thérapeutique. Nouv Presse Med 1972; 1: 3057-61.

5 Wellens HJJ, Bär FWHM, Lie KI, Düren Dr, Dohmen HJ. Effect of procainamide, propanolol and verapamil on mechanism of tachycardia in patients with chronic recurrent ventricular tachycardia. Am $\mathcal{F}$ Cardiol 1977; 40: 579-85.

6 Wellens HJJ, Schuilenburg RM, Durrer D. Electrical stimulation of the heart in patients with ventricular tachycardia. Circulation 1972; 46: 216-26.

7 Cranefield PF, Aronson RS. Initiation of sustained rhythmic activity by single propagated action potentials in canine cardiac Purkinje fibers exposed to sodium-free solution or to ouabain. Circ Res 1974; 34: 477-81.

8 Rosen MR, Ilvento JP, Gelband H, Merker C. Effects of verapamil on electrophysiologic properties of canine cardiac Purkinje fibres. F Pharmacol Exp Ther 1974; 189: 414-22.

9 Spear JF, Horowitz LN, Hodess AB, MacVaugh H 3rd, Moore EN. Cellular electrophysiology of human myocardial infarction. I - Abnormalities of cellular activation. Circulation 1979; 59: 247-56. 
10 Cranefield PF, Aronson RS, Wit AL. Effect of verapamil on the normal action potential and on a calcium dependent stow response of canine cardiac Purkinje fibers. Circ Res 1974; 34: 204-13.

11 Coumel P, Leclercq JF, Atruel P, et al. Tachycardies ventriculaires en salves. Étude electrophysiologique et therapeutique. Arch Mal Coeur 1980; 73: 153-64.
12 Zipes DP, Foster PR, Troup PJ, Pedersen DH. Atrial induction of ventricular tachycardia - reentry versus triggered automaticity. Am $\mathcal{F}$ Cardiol 1979; 44: 1-8.

Requests for reprints to Dr B Belhassen, Department of Cardiology, Ichilov Hospital, Tel-Aviv, Israel. 